Check for updates

Cite this: Chem. Commun., 2017, 53, 12325

Received 2nd October 2017, Accepted 27th October 2017

DOI: $10.1039 / c 7 c c 07654 a$

rsc.li/chemcomm

\section{Synthesis of $\mathrm{P}_{2} \mathrm{C}_{2} \mathrm{O}_{2}$ and $\mathrm{P}_{2} \mathrm{CO}$ via NHC-mediated coupling of the phosphaethynolate anion $\dagger$}

\author{
Robert J. Gilliard, Jr., (D) ${ }^{a b}$ Riccardo Suter, (D) ${ }^{b}$ Erik Schrader, (D) ${ }^{b}$ Zoltán Benkő, (D) \\ Arnold L. Rheingold, (D) ${ }^{d}$ Hansjörg Grützmacher (D)*b and John D. Protasiewicz (D)*a
}

The reaction of the chloroimidazolium chloride salt, $[\mathrm{NHC}-\mathrm{Cl}][\mathrm{Cl}]$, $\mathrm{NHC}=\mathrm{C}\left\{\mathrm{N}\left(2,6-{ }^{\mathrm{i}} \mathrm{Pr}_{2} \mathrm{C}_{6} \mathrm{H}_{3}\right) \mathrm{CH}\right\}_{2}$ (1) with two equivalents of sodium phosphaethynolate, $\mathrm{Na}[\mathrm{OCP}]$.(dioxane $)_{2.5}$, results in the formation of NHC-\{cyclo-(CO)- $\left.\mathrm{P}_{2}-\mathrm{C}(\mathrm{O})\right\}$ (2) and NHC- $\mathrm{P}_{2}-\mathrm{C}(\mathrm{O})-\mathrm{NHC}$ (3). Notably, in the presence of free NHC ligand, compound 2 converts to compound 3 via extrusion of $\mathrm{CO}$ at elevated temperatures. The nature of the bonding in these complexes was probed computationally and spectroscopically.

Over the past decade, a large number of main group atoms and units have been isolated using stable carbenes. ${ }^{1}$ These fascinating molecules have provided insight into fundamental issues of structure and bonding and have spawned new applications in main group chemistry. Prominent examples germane to this report include main group diatomics and unusual heterocycles containing CO functionalities. Indeed, Robinson and coworkers showed that $\mathrm{P}_{2}$ could be stabilized by potassium graphite reduction of an $\mathrm{NHC}_{-} \mathrm{PCl}_{3}$ adduct to afford NHC- $\mathrm{P}_{2}-\mathrm{NHC} \mathbf{A}$ (Fig. 1). ${ }^{2}$ Compound $\mathbf{A}$ reacts with molecular oxygen to form a molecule containing a diphosphorus tetroxide unit, NHC-P(O)-P(O)-NHC. ${ }^{3}$ Bertrand et al. prepared bis-[cyclic(alkyl)amino carbene] diphosphorus complex B (CAAC- $\mathrm{P}_{2}$-CAAC) by the direct reaction of CAAC with $\mathrm{P}_{4}$ and demonstrated its reactivity in the formation of carbenestabilized $\mathrm{P}_{2}$-radical cation and $\mathrm{P}_{2}$-dication. ${ }^{4}$ Recently, Braunschweig and coworkers utilized an NHC-stabilized diboryne ${ }^{5}$ to generate bis(boroketene) C. $^{6}$ Compound $\mathbf{C}$ could be converted to the bicyclic bis(boralactone) $\mathbf{D}$ in the presence of $\mathrm{CO}^{7}$ As $\mathrm{CO}$ coordination to

\footnotetext{
${ }^{a}$ Department of Chemistry, Case Western Reserve University, Cleveland, $\mathrm{OH} 44106$, USA. E-mail: Protasiewicz@case.edu

${ }^{b}$ Department of Chemistry and Applied Biosciences, ETH Zurich, CH-8093 Zurich, Switzerland. E-mail: hgruetzmacher@ethz.ch

${ }^{c}$ Budapest University of Technology and Economics, H.111 Budapest Szent Gellért tér 4, Hungary

${ }^{d}$ Department of Chemistry, University of California, San Diego, La Jolla, CA 92093, USA

$\dagger$ Electronic supplementary information (ESI) available. CCDC 1536982 (3) and 1536983 (2). For ESI and crystallographic data in CIF or other electronic format see DOI: $10.1039 / \mathrm{c} 7 \mathrm{cc} 07654 \mathrm{a}$
}<smiles></smiles><smiles></smiles>

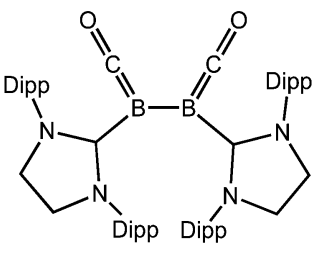

C

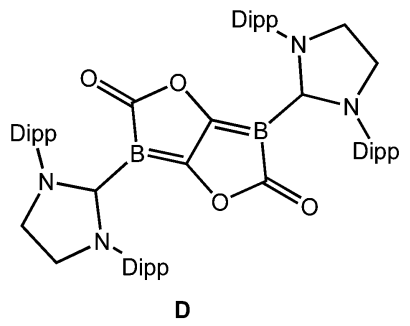

D
Fig. 1 Examples of NHC-stabilized main group species. ${ }^{2,4,6}$

main group elements is rare, the latter examples (C and $\mathbf{D})$ serve as important contributions to the discussion of main group molecules that mimic bonding arrangements typically associated with transition metals. ${ }^{7,8}$

Recently, we have been exploring the chemistry of sodium phosphaethynolate, $\mathrm{Na}[\mathrm{OCP}]$, which can be viewed as a hybrid of three resonance structures, a phosphaethynolate $[\mathrm{O}-\mathrm{C} \equiv \mathrm{P}]^{-}$, a phosphaketenide $[\mathrm{O}=\mathrm{C}=\mathrm{P}]^{-}$and a $\mathrm{P}$-transfer reagent $[\mathrm{O} \equiv \mathrm{C} \rightarrow \mathrm{P}]^{-}$. This remarkably stable synthon has been shown to afford cycloaddition chemistry, and, participate in salt metathesis reactions to provide facile routes to novel organophosphorus heterocycles and small molecules. ${ }^{9-25}$ Therefore, we reasoned that it would be possible to utilize $\mathrm{Na}[\mathrm{OCP}]$ as a building block to study the coordination chemistry of compounds which contain the formal elements of $\mathrm{P}_{2}$ and CO. Herein, we report the synthesis, molecular structures, and computational studies of NHC- $\left\{\right.$ cyclo- $\left.(\mathrm{CO})-\mathrm{P}_{2}-\mathrm{C}(\mathrm{O})\right\}(2)$ and NHC- $\mathrm{P}_{2}-\mathrm{C}(\mathrm{O})-\mathrm{NHC}(3), \mathrm{NHC}=$ $\mathrm{C}\left\{\mathrm{N}\left(2,6-{ }^{\mathrm{i}} \mathrm{Pr}_{2} \mathrm{C}_{6} \mathrm{H}_{3}\right) \mathrm{CH}\right\}_{2}$. Notably, the isolation of these highly reactive molecules represent unusual examples of $\mathrm{P}-\mathrm{P}$ coupled materials derived from the phosphaethynolate anion, $[\mathrm{OCP}]^{-}$. 


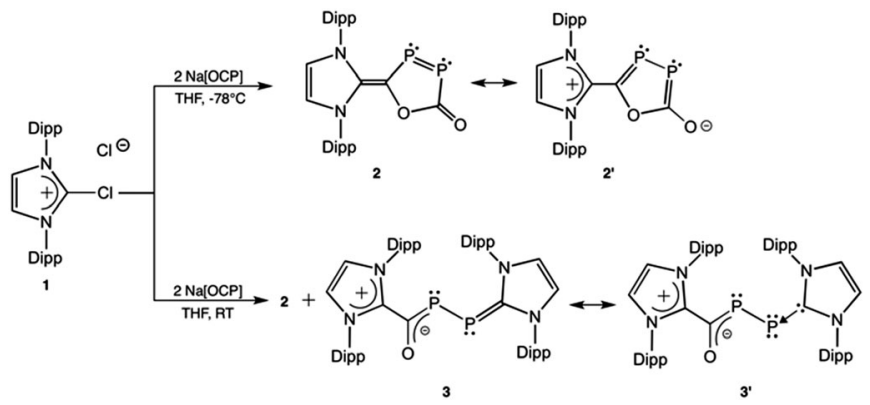

Scheme 1 Synthesis of compounds 2 and $\mathbf{3}$

Compounds 2 and 3 were obtained in different ratios depending on the specific reaction conditions (Scheme 1; Dipp = 2,6-diisopropylphenyl). When two equivalents of $\mathrm{Na}(\mathrm{OCP})$. (dioxane $)_{2.5}$ is added to a suspension of [NHC-Cl][Cl] (1) in THF at $-78{ }^{\circ} \mathrm{C},{ }^{31} \mathrm{P}$ NMR of the reaction mixture indicates a single product $\left(\delta=299.0 \mathrm{ppm}, 74.6 \mathrm{ppm},{ }^{1} J_{\mathrm{p}, \mathrm{p}}=484 \mathrm{~Hz}\right.$ ), attributable to new red species 2 . Compound 2 can be isolated in $34 \%$ yield via toluene extraction of the solid reaction mixture and subsequent washing with hexanes. If the reaction is performed at room temperature, compound 2 is isolated in significantly higher yield (62\%) as well as a second green compound 3 in 13\% yield. The characteristic ${ }^{1} \mathrm{H}$ NMR imidazole resonance of 2 at $\delta=6.03 \mathrm{ppm}$ differs from the two resonances observed for $3(\delta=5.89,6.04 \mathrm{ppm})$, which indicate the presence of two chemically inequivalent NHC ligands. The proton-coupled ${ }^{31} \mathrm{P}$ NMR spectrum of 3 , exhibits two doublets at $\delta=153.5 \mathrm{ppm}$ and $\delta=-5.09 \mathrm{ppm}\left({ }^{1} J_{\mathrm{p}, \mathrm{p}}=304 \mathrm{~Hz}\right)$, consistent with decreased $\mathrm{P}-\mathrm{P}$ bond order compared to the heterocycle 2 . These shifts differ significantly from the ${ }^{31} \mathrm{P}$ NMR chemical shifts reported for biscarbene- $\mathrm{P}_{2}$ adducts $\mathbf{A}(\delta=-52.4 \mathrm{ppm})^{2}$ and $\mathbf{B}(\delta=+54.4 \mathrm{ppm}){ }^{4}$ Compound 2 is stable under inert atmosphere in a benzene- $d_{6}$ or toluene solution at room temperature for $c a .2$ weeks. However, compound 3 is unstable in solution at room temperature and significantly more prone to side reactions which produce free NHC. As compound 3 and free NHC ligand have very similar solubility, it has proved difficult to completely separate the two compounds on a preparative scale.

Red air- and moisture-sensitive needle-shaped crystals of 2 suitable for a single crystal X-ray diffraction study were grown from a THF: toluene $(5: 1)$ solution at $-35{ }^{\circ} \mathrm{C}$ (Fig. 2). The structure of 2 reveals two di-coordinate phosphorus atoms within a five-membered heterocyclic ring. Green air- and moisture-sensitive block-shaped crystals of 3 were isolated from a concentrated hexanes solution at $-35{ }^{\circ} \mathrm{C}$ (Fig. 3). Structural analysis of 3 shows two di-coordinate phosphorus atomic centers with an open chain structure. The P-P bond distance in 2, $2.093 \AA$, is between a P-P single bond $(\sim 2.20 \AA)^{26}$ and a $\mathrm{P}=\mathrm{P}$ double bond $(\sim 2.00 \AA) .{ }^{27}$ Accordingly, the $\mathrm{P}-\mathrm{P}$ bond distance in 2 is shorter than $3(2.153 \AA)$, which has more single bond character. Indeed, these values are in agreement with the P-P bond distances in NHC- $\mathrm{P}_{2}$-NHC A $(2.205 \AA),{ }^{2}$ CAAC-P $\mathrm{P}_{2}$-CAAC B $(2.184 \AA),{ }^{4}$ and $\left[\mathrm{NHC}-\mathrm{P}_{2}-\left(\mathrm{N}^{\mathrm{i}} \mathrm{Pr}_{2}\right)\right]\left[\mathrm{GaCl}_{4}\right](2.061 \AA) .{ }^{24} \mathrm{The} \mathrm{C}(29)-\mathrm{P}(2)$ bond distance in $3(1.799 \AA)$ is comparable to the $\mathrm{C}-\mathrm{P}$ bond in $\mathbf{A}$

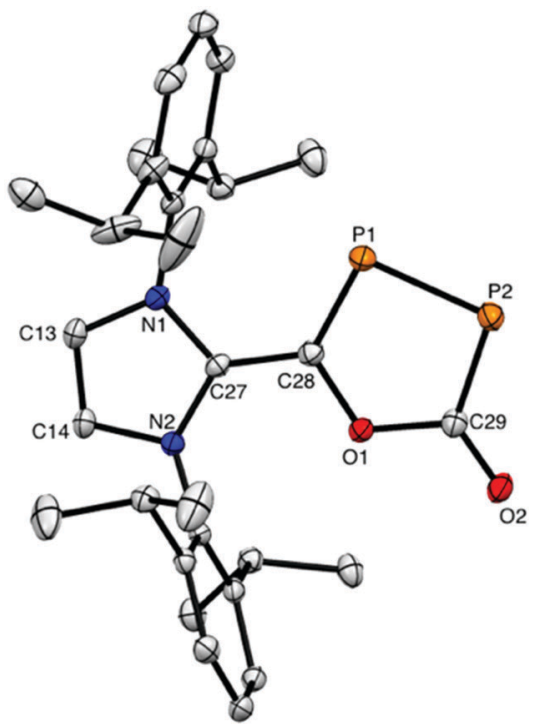

Fig. 2 Molecular structure of $\mathbf{2}$ (thermal ellipsoids at 30\% probability; $\mathrm{H}$ atoms, cocrystallized THF, and toluene molecule are omitted for clarity). Selected bond distances (Å) and angles ( ${ }^{\circ}$ : P1-P2: 2.093(1); C27-C28: 1.437(4); P1-C28: 1.719(3); P2-C29: 1.799(4); C28-O1: 1.377(3); C29-O1: 1.414(4); C29-O2 1.212(4). C28-P1-P2: 94.5(1); P1-P2-C29: 94.4(1); C27-C28-P1 127.7(2); C27-C28-O1: 112.4(2); P2-C29-O1: 115.2(2); P1-C28-O1: 120.0(2).

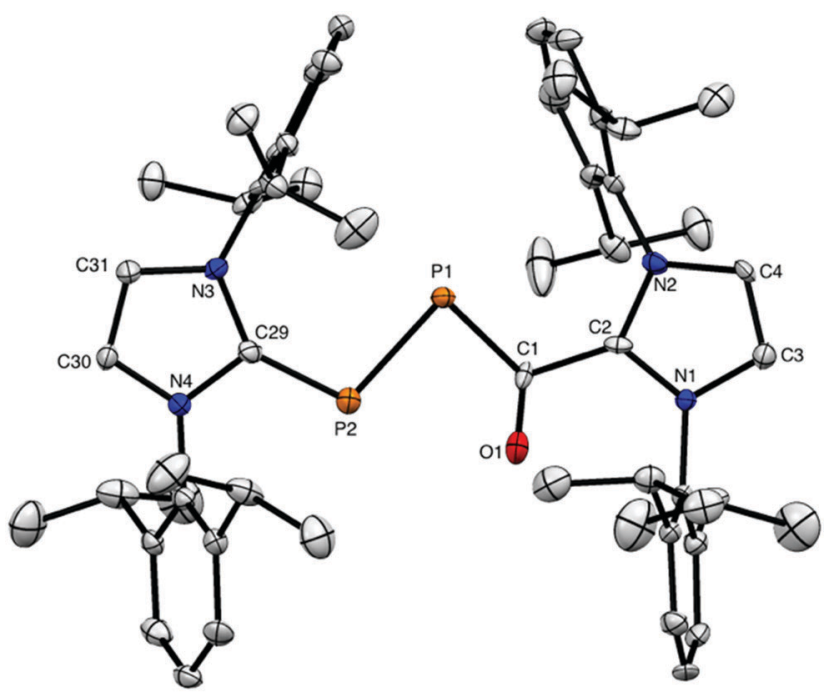

Fig. 3 Molecular structure of 3 (thermal ellipsoids at 30\% probability; $\mathrm{H}$ atoms and cocrystallized dioxane molecule are omitted for clarity). Selected bond distances ( $(\AA)$ and angles ( $\left.{ }^{\circ}\right)$ : P1-P2: 2.153(3); P1-C1: 1.798(9); P2-C29: 1.760(9); C1-O1 1.16(1); C29-O1: 1.414(4). C29-P2-P1: 104.8(3), P2-P1-C1: 88.0(3), P1-C1-C2: 115.3(6); O1-C1-C2: 113.7(7).

$(1.750 \AA)$ which is slightly longer than in $\mathbf{B}(1.719 \AA)$. Moreover, this data is in the range of the $\mathrm{C}(28)-\mathrm{P}(1)[1.719 \AA]$ and $\mathrm{C}(29)-\mathrm{P}(2)$ [1.799 $\mathrm{A}]$ bond distance of 2 .

Remarkably, at $55-60{ }^{\circ} \mathrm{C}$ in benzene- $d_{6}$, and in the presence of free NHC ligand, compound 2 extrudes $\mathrm{CO}$ to form the more reactive compound $\mathbf{3}$. The reaction progress is easily monitored by ${ }^{31} \mathrm{P}$ NMR spectroscopy, as shown in Fig. 4. An initial spectrum was taken of 2 and free NHC at room temperature 


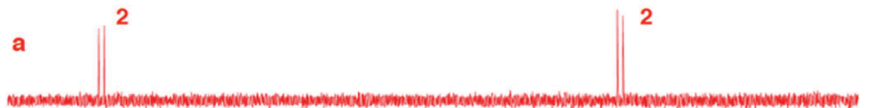

b
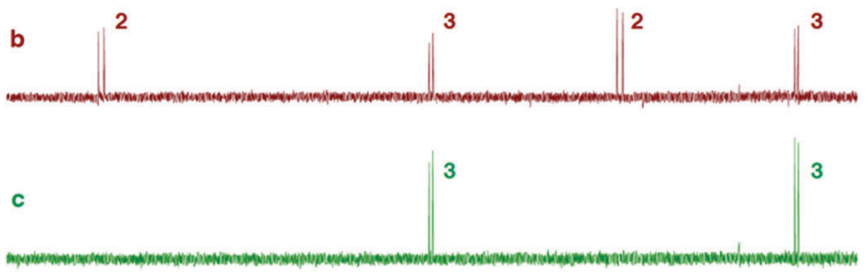

$\begin{array}{llllllllllllllllll}320 & 300 & 280 & 260 & 240 & 220 & 200 & 180 & 160 & 140 & 120 & 100 & 80 & 60 & 40 & 20 & 0 & -20\end{array}$

Fig. $4{ }^{31} \mathrm{P}\left\{{ }^{1} \mathrm{H}\right\}$ NMR spectra for the reaction of $\mathbf{2}$ with free NHC to afford 3 via extrusion of $\mathrm{CO}$ at $55-60{ }^{\circ} \mathrm{C}$ in benzene- $d_{6}$. (a) Compound $2, t=0 \mathrm{~min}$; (b) compounds 2 and $3, t=15 \mathrm{~min}$; (c) compound $3, t=30 \mathrm{~min}$.

(Fig. 4, red trace, a). After 15 min of heating, 2 and 3 can be observed in solution (Fig. 4, maroon trace, b). Complete conversion of 2 to 3 by ${ }^{31} \mathrm{P}$ NMR is observed after $30 \mathrm{~min}$ (Fig. 4, green trace, c). Although the mechanism is unclear, the reaction may proceed via nucleophilic attack on phosphorus by the free carbene and subsequent loss of $\mathrm{CO}$ to form 3. It is noteworthy that heating compound 2 by itself (without free NHC) in benzene- $d_{6}$ does not afford 3 . If the temperature exceeds $60{ }^{\circ} \mathrm{C}$, other products are produced, one of which was identified as $\mathrm{NHC}_{2} \mathrm{P}_{2}$-NHC (A). ${ }^{2}$ Attempts were made to convert $\mathbf{3}$ to $\mathbf{A}$ via extrusion of $\mathbf{C O}$, and though some of compound $\mathbf{A}$ was observed, there were a number of unidentifiable phosphoruscontaining species. Based on these results, we believe that the formation of $\mathbf{3}$ from $\mathbf{1}$ in the room temperature reaction is due to the exothermic nature of the reaction in which some free NHC ligand is produced under highly reducing conditions, facilitating a reaction similar to that described in Fig. 4. Indeed, Bertrand reported that NHCs are incapable of capturing $\mathrm{CO},{ }^{25}$ therefore, unreacted NHC remains free in solution until it interacts with phosphorus to stabilize the $\mathrm{P}_{2} \mathrm{C}(\mathrm{O})$ moiety.

To gain a deeper insight into the bonding of these reactive molecules, density functional theory calculations at the $\omega \mathrm{B} 97 \mathrm{XD} /$ aug-cc-pVDZ level were performed on a simplified system where the Dipp groups have been replaced with methyl substituents. In $\mathbf{2 M}$, the computational data is in agreement with the experimental results (for more details including atoms in molecules analysis see the ESI $\dagger$ ). The Wiberg bond index (WBI) of the P-P bond in $2 \mathrm{M}$ is 1.45 and the computed bond distance is $2.088 \AA$, both supporting partial double bond character. This thereby suggests a moderate degree of $\pi$-interaction in the oxadiphosphole ring which is also reflected in the increased bond order of the $\mathrm{C}-\mathrm{P}$ bond $(\mathrm{WBI}=1.27)$ adjacent to the carbene. However, there is no indication of cyclic delocalization since the bonding parameters of the $\mathrm{P}-\mathrm{C}$ bond is in the range of a typical $\mathrm{P}-\mathrm{C}$ single bond. The (NHC) $-\mathrm{C}$ bond order in $\mathbf{2} \mathbf{M}$ is somewhat larger (1.419 $\AA$, WBI = 1.26) than the similar $(\mathrm{NHC})-\mathrm{C}$ bond in $3 \mathbf{M}$ (1.501 $\mathrm{A}, \mathrm{WBI}=1.01$ ), indicating increased double bond character. Among the $\mathrm{C}-\mathrm{O}$ bonds, the endocyclic ones can be described as single bonds, however, the exocyclic $\mathrm{C}-\mathrm{O}$ bond is considerably shorter $(\mathrm{WBI}=1.69)$. Based on these results, compound 2 is best represented as a hybrid of resonance structures 2 and $2^{\prime}$ with significant electron delocalization throughout the (NHC)-C-P-P fragment.

With regard to $\mathbf{3 M}$, the bonding situation in the (NHC)-P fragment is similar to what is observed in known NHC-phosphinidene adducts $\mathrm{NHC}-\mathrm{PH}^{26}$ and $\mathrm{NHC}-\mathrm{P}_{2}-\mathrm{NHC},{ }^{2}$ which are described as a single bond with some double bond character (i.e., donation of an electron pair from the NHC and back-donation from the phosphorus lone pair). Indeed, the WBI of 1.28 for the (NHC)-P bond in $\mathbf{3} \mathbf{M}$ indicates a bond being somewhat stronger than a single bond. Furthermore, the NHC fragment attached to the P atom in $\mathbf{3} \mathbf{M}$ is almost neutral (the sum of partial charges over this moiety is $+0.135 e$ ), which implies that the contribution of a zwitterionic resonance structure $\left[\right.$ e.g. $\left.(\mathrm{NHC})^{+}-\mathrm{P}^{-}\right]$is negligible. The $\mathrm{P}-\mathrm{P}$ bond in $\mathbf{3} \mathbf{M}$ corresponds to a single bond $(\mathrm{WBI}=1.04)$ which is in accord with the WBI $(1.04)^{2}$ of the $\mathrm{P}-\mathrm{P}$ bond in $\mathrm{A}$. In notable contrast, the $\mathrm{P}-\mathrm{C}$ bond in the [PCO] fragment of 3 has double bond character, exhibited by the increased WBI of 1.35. Moreover, the $\mathrm{P}-\mathrm{C}$ bond in $\mathbf{3 M}(1.754 \AA)$ is shorter than the (NHC)-P bond (1.783 $\AA$ ). The $\mathrm{C}-\mathrm{O}$ bond of 3 is stronger than a normal single bond, which is indicated by the increased WBI (1.41) and by the shorter bond length in 3M (1.255 $\AA$ ) compared to a prototypical single bond (1.419 $\AA$ in $\left.\mathrm{H}_{3} \mathrm{C}-\mathrm{OH}\right)$. Thus, the bonding properties of the $\mathrm{P}-\mathrm{C}$ and $\mathrm{C}-\mathrm{O}$ bonds unambiguously confirm a significant $\pi$-delocalization over the $\mathrm{P}-\mathrm{C}-\mathrm{O}$ moiety. As the (NHC)-C bond has been found to be a single bond $(\mathrm{WBI}=1.04)$, there is no significant $\pi$-delocalization between the PCO unit and the attached carbene moiety. However, the partial charges clearly show that the second NHC unit (bound to the carbon atom) carries positive charge (sum of NPA charges in the NHC fragment is $+0.479 e$ ), while the $\mathrm{O}$ atom of the carbonyl group has a negative charge $(-0.720 e)$. These results lead us to a conclusion that compound $\mathbf{3}$ is best represented as resonance structure $3^{\prime}$ shown in Scheme 1.

The structural assignments for $\mathbf{2}$ and $\mathbf{3}$ are also supported by the MO representations (Fig. 5). In 2, the HOMO reflects the resonance structure $2^{\prime}$ with the exocyclic $\mathrm{O}$ anion and some $\pi$-delocalization, while the HOMO-2 is mainly the PP $\pi$-bond (cf. mesomeric structure 2). In 3, the HOMO represents the proposed resonance structure $\mathbf{3}^{\prime}$ (i.e., delocalization at the PPCO unit).

This work demonstrates the versatility of sodium phosphaethynolate as a synthon to access highly reactive, low-oxidationstate phosphorus species with unprecedented bonding modes. Reaction of salt [NHC-Cl][Cl] 1 with $\mathrm{Na}[\mathrm{OCP}]$ affords 2 , a heterocycle containing a $\mathrm{P}_{2}$ unit connected to two CO fragments, and 3, a $\mathrm{P}_{2}$ moiety bound to one CO, both stabilized by NHCs. Notably, CO can be extruded from 2 to form 3, which then can be partially converted to A. As 2 and 3 possess electron rich phosphorus centers, these complexes will be explored as ligands for main group and transition metal species.

We are grateful to the National Science Foundation (CHE1464855), the ETH Zürich and the Swiss National Science Foundation (SNF) for funding. R. J. G. thanks the UNCF-Merck 

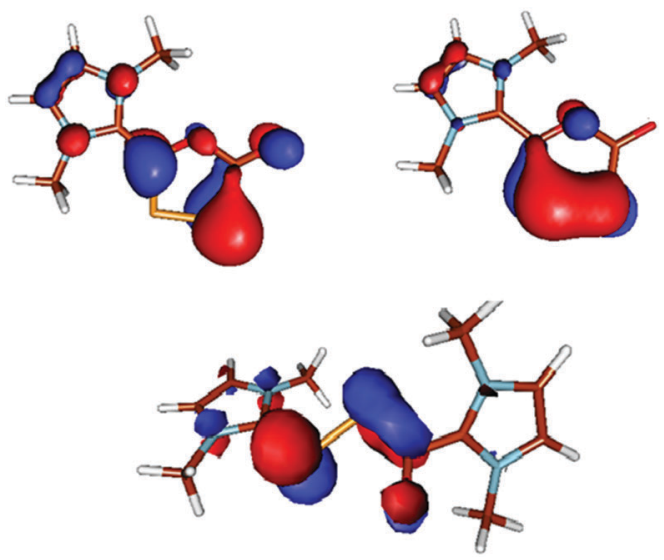

Fig. $5 \mathrm{HOMO}$ and $\mathrm{HOMO}-2$ for 2 (top left and right, respectively). $\mathrm{HOMO}$ for 3 (bottom).

Fellowship program and the Ford Foundation for postdoctoral awards. Z. B. is grateful to the NKFIH (PD 116329) and the János Balyai Research Fellowship. We also appreciate Dr. Michael Wörle of the Small Molecule Crystallography Center at ETH Zürich for helpful discussions.

\section{Conflicts of interest}

There are no conflicts to declare.

\section{Notes and references}

1 For reviews on main group molecules isolated using stable carbenes: (a) Y. Wang and G. H. Robinson, Inorg. Chem., 2011, 50, 12326-12337; (b) C. D. Martin, M. Soleilhavoup and G. Bertrand, Chem. Sci., 2013, 4, 3020-3030; (c) D. D. Wilson and J. L. Dutton, Chem. - Eur. J., 2013, 41, 13626-13637; (d) Y. Wang and G. H. Robinson, Inorg. Chem., 2014, 53, 11815-11832; (e) M. Soleilhavoup and G. Bertrand, Acc. Chem. Res., 2015, 48, 256-266; $(f)$ M. Malaimi, R. Jazzar, M. Soleilhavoup and G. Bertrand, Angew. Chem., Int. Ed., 2017, 56, 10046-10068.

2 Y. Wang, Y. Xie, P. Wei, R. B. King, H. F. Schaefer, III, P. V. R. Schleyer and G. H. Robinson, J. Am. Chem. Soc., 2008, 130, 14970-14971.

3 Y. Wang, Y. Xie, P. Wei, H. F. Schaefer, III, P. V. R. Schleyer and G. H. Robinson, J. Am. Chem. Soc., 2013, 135, 19139-19142.
4 O. Back, B. Donnadieu, P. Parameswaran, G. Frenking and G. Bertrand, Nat. Chem., 2010, 2, 369-373.

5 H. Braunschweig, R. D. Dewhurst, K. Hammond, J. Mies, K. Radacki and A. Vargas, Science, 2012, 336, 1420-1422.

6 J. Böhnke, H. Braunschweig, T. Dellermann, W. C. Ewing, K. Hammond, J. O. C. Jimenez-Halla, T. Kramer and J. Mies, Angew. Chem., Int. Ed., 2015, 54, 13801-13805.

7 H. Braunschweig, R. D. Dewhurst, F. Hupp, M. Nutz, K. Radacki, C. W. Tate, A. Vargas and Q. Ye, Nat. Chem., 2015, 522, 327-330.

8 P. P. Power, Nature, 2010, 463, 171-177.

9 G. Becker, W. Schwarz, N. Seidler and M. Westerhausen, Z. Anorg. Allg. Chem., 1992, 612, 72-82.

10 F. F. Puschmann, D. Stein, D. Heift, C. Hendriksen, Z. A. Gal, H. F. Grützmacher and H. Grützmacher, Angew. Chem., Int. Ed., 2011, 50, 8420-8423.

11 D. Heift, Z. Benkő and H. Grützmacher, Dalton Trans., 2014, 43, 831-840.

12 T. P. Robinson and J. M. Goicoechea, Chem. - Eur. J., 2015, 21, 5727-5731.

13 X. Chen, S. Alidori, F. F. Puschmann, G. Santiso-Quinones, Z. Benkő, Z. Li, G. Becker, H. F. Grützmacher and H. Grützmacher, Angew. Chem., Int. Ed., 2014, 53, 1641-1645.

14 D. Heift, Z. Benkő and H. Grützmacher, Chem. - Eur. J., 2014, 20, 11326-11330.

15 D. Heift, Z. Benkő and H. Grützmacher, Dalton Trans., 2014, 43, 831-840.

16 L. Liu, J. Zhu and Y. Zhao, Chem. Commun., 2014, 50, 11347-11349.

17 T. P. Robinson, M. J. Cowley, D. Scheschkewitz and J. M. Goicoechea, Angew. Chem., Int. Ed., 2015, 54, 683-686.

18 C. Camp, N. Settineri, J. Lèfevre, A. Jupp, J. M. Goicoechea, L. Maron and J. Arnold, Chem. Sci., 2015, 6, 6379-6384.

19 A. R. Jupp and J. M. Goicoechea, J. Am. Chem. Soc., 2013, 135, 19131-19134.

20 R. Suter, Y. Mei, M. Baker, Z. Benkö, Z. Li and H. Grützmacher, Angew. Chem., Int. Ed., 2017, 56, 1356-1360.

21 M. Hansmann, D. Ruiz, L. Liu, R. Jazzar and G. Bertrand, Chem. Sci., $2017,8,3720-3725$.

22 J. M. Kieser, R. J. Gilliard, Jr., A. L. Rheingold, H. Grützmacher and J. D. Protasiewicz, Chem. Commun., 2017, 53, 5110-5112.

23 L. N. Grant, B. Pinter, B. C. Manor, R. Suter, H. Grützmacher and D. J. Mindiola, Chem. - Eur. J., 2017, 23, 6272-6276.

24 A. Beil, R. J. Gilliard Jr. and H. Grützmacher, Dalton Trans., 2016, 45, 2044-2052.

25 V. Lavallo, Y. Canac, B. Donnadieu, W. W. Schoeller and G. Bertrand, Angew. Chem., Int. Ed., 2006, 45, 3488-3491.

26 A. M. Tondreau, Z. Benkő, J. R. Harmer and H. Grützmacher, Chem. Sci., 2014, 5, 1545-1554.

27 J. D. Protasiewicz, M. P. Washington, V. B. Gudimetla, J. L. Payton and M. C. Simpson, Inorg. Chim. Acta, 2010, 364, 39-45. 